\title{
I.U.C.A.F AND FREQUENCIES FOR RADIO ASTRONOMY
}

\author{
JOHN W. FINDLAY
}

Senior Scientist at the National Radio Astronomy Observatory until retirement in 1985

\section{INTRODUCTION}

Many papers in the Colloquium describe the difficulties which now exist when radio astronomers try to make highly sensitive observations in various regions of the spectrum. The author has been involved for about 30 years in attempts to get parts of the radio spectrum "protected" so that radio observations could be made in these regions free from damaging interference. Thus it may be interesting in this paper to look backward to the work done by many people before and during the International Telecommunications Union (ITU) World Administrative Radio Conference (WARC) of 1959, and to describe briefly the outcome of that WARC.

The need to have bands of frequencies preserved for radio astronomy was first discussed at URSI in Zurich in 1950, and between then and 1957 the subject was studied by the IAU and URSI. When URSI met in 1957, Sub-Commission $\mathrm{V}(\mathrm{e})$ was formed to prepare, with the IAU, for the WARC to be held in late 1959. The author became Chairman of V(e) in the spring of 1958.

\section{WORK WITHIN THE CCIR}

The first need was for radio astronomers to state which bands of the spectrum were of the greatest scientific importance to them. This statement should have international support. Since the International Radio Consultative Committee (CCIR) is the body charged with giving agreed scientific and technical advice to the ITU, it was the correct body to present the views of the scientists. Action to bring this about had been started in URSI in 1950, when a Resolution was passed to the CCIR asking for channels to be kept clear for radio astronomy (RA). The CCIR responded in Geneva (1951) with Resolution 56. This spelled out the request for clear bands from $40 \mathrm{MHz}$ to $3 \mathrm{GHz}$. Unfortunately, when URSI met in Australia in 1952, Commission V said that it was "impracticable to use the frequencies specified for solar observations". The CCIR then (London 1953) withdrew \# 56 in favor of a more general statement. Only after URSI met in the Hague (1954) was CCIR asked to return to the protection of the H-line and the continuum bands; then the CCIR accepted a new Resolution \# 173 in Warsaw in 1956. This now referred to the deuterium, hydrogen and $\mathrm{OH}$ lines, though only hydrogen had been observed. When sub-Commission V(e) was set 
up by URSI in 1957, CCIR Resolution 173 was still the relevant document.

This story has been retold, because, as will be seen later, it was important in the formation of at least one national position prior to the 1959 WARC. As V(e) started, a better CCIR document was needed, since the CCIR Plenary in Los Angeles to be held in April 1959 was the last one before the 1959 WARC. In preparing the agreed international position on the frequency bands to be included in this new paper, I was able to rely on opinions gathered in August 1959 from the Netherlands, the UK, France and Belgium during a visit to Europe in October 1958. I had believed that the IAU at the Moscow Assembly (August 1958) had passed a detailed Resolution which was in line with the opinions I had collected. This was not so; the formal wording was only general, but IAU Commission 40 had produced an excellent paper during the IAU Symposium in Paris (August 1958). This was the basis of the paper offered to the CCIR in Los Angeles, and it was agreed and published as Recommendation 314. Thus the first step was successfully taken. The countries who responded and helped in this process were the Netherlands, the UK, Belgium, France, and the USA. The Chairman of CCIR Study Group IV, which dealt with 314, was Dana K. Bailey of the USA.

\section{PREPARING FOR THE WARC}

The 1959 WARC was essentially the first full Conference since World War II, although there had been a WARC in Atlantic City in 1947. But since then, both RA and the space age had started, COSPAR was in existence so the first requests for both RA and Space Science were to be considered at the WARC. Professor Jan Oort (IAU President and a major actor in the work being described), Professor H.C. van de Hulst (President of COSPAR) and Lloyd Berkner (President of URSI and also a major actor in the work) were all agreed that there should be at least one representative of the three Unions throughout the WARC. This was a major commitment, since the schedule called for a conference lasting four months, and, as Oort wrote to the IAU General Secretary, "Per diem in Geneva is $\$ 15.00$." Nevertheless, it was agreed and Oort named himself, Van de Hulst, Balth van der Pol and Charles Seeger to serve. W.J.G. Beynon from the UK, R. Coutrez from Belgium and I completed the list.

By the end of the CCIR Plenary it was clear that there would be positive positions taken at the WARC in support of the need to clear the H-line and also to set clear bands throughout the spectrum from $40 \mathrm{MHz}$ to above $10 \mathrm{GHz}$. Although differing in detail, at least the Netherlands and the UK proposals were good, and there would be support from other Administrations. However, it was also known that the USA would support only $1400-1427 \mathrm{MHz}$ as a world-wide (WW) exclusive band; the rest would be left to "local arrangements."

This US position had been arrived at after lengthy study organized by the State Department. Radio astronomers had been included in the discussions, which of course also involved most of the civil and military users of the spectrum. It is not possible to assign any one reason now for the weakness of the RA position. But, as has been indicated in paragraph 2 , the apparent inability of the international astronomers to state their views to the CCIR was certainly a contributing factor. 
After the CCIR Plenary, an attempt was made by me and Otto Struve, the recently appointed first Director of NRAO, to request a change in the US position for the WARC. Dr. Struve knew Dr. Kistiakowski, who had just been chosen as Science Advisor by President Eisenhower. Accordingly, Otto and I met with Dr. Kistiakowski on July 15th 1959. The meeting is recorded in Dr. K's memoirs, which are correct except that I am listed as John W. Finney of the New York Times. I was asked to visit Dr. Wallace Brode, the Science Advisor to the Secretary of State, to tell him of the international situation and of my actions. This I did; but, in a not very satisfactory meeting, I do not believe my message got across. At any rate, when the WARC convened on August 17th 1959 we found the US position unchanged.

\section{THE 1959 WARC}

The first phase lasted about 5 weeks, and the various proposals were studied by working groups of various sizes. Professors Oort and Van de Hulst visited and both gave lectures on RA. Most unfortunately, Dr. van der Pol, who was already in bad health, died in October. The main burden fell on Charles Seeger, who was our observer during most of this period. The "observer" status gives access to all papers and to working group and Plenary sessions. But an observer cannot speak on any subject unless so requested. His task, therefore, involves a great deal of talking and writing outside the formal work of the WARC.

By mid September it was clear that the RA discussions had reached an impasse. The Netherlands, the UK and some others were coming together along the lines of CCIR 314. The United States was adhering to its original position. At about this time both Otto Struve and Leo Goldberg spoke to the Press, and Walter Sullivan wrote an article in the New York Times with the headline "U.S. STAND SCORED ON RADIO AND SPACE." There was also an article by John Lear in the Saturday Review.

This publicity caused trouble. At least one member of the U.S. Delegation flew back from Geneva to attend a day and a half of meetings at the National Academy of Sciences on October 16 th and 17 th at which many officials and radio astronomers were present. The outcome of this meeting was a major change of the policy of the United States. John W. Finney reported this meeting in the New York Times.

When I arrived in Geneva on October 22nd the US Delegation had already presented a WARC paper which became Recommendation 32 of the Conference, and work began to help RA as much as was still possible.

\section{AFTER THE WARC}

The final outcome of the WARC fell considerably below the hopes of radio astronomers, but the following main points were gained:

(a) Radio Astronomy was recognized as a "Service" in the ITU.

(b) The H-line was protected WW in the Radio Regulations.

(c) Some minimal protection, usually in footnote form, was given to many 
spectral bands from about $70 \mathrm{MHz}$ to $31.5 \mathrm{GHz}$.

(d) It was agreed that the needs of RA and Space would be included in the "Space" WARC expected to be held in 1963.

\section{THE FORMATION OF IUCAF}

URSI commission V(e) reported the outcome of its work at the General Assembly held in London in 1960 . In that Report was a recommendation that URSI, the IAU and COSPAR should form an international body to continue to work to obtain and protect radio frequencies for the three sciences. This was started in London, where Lloyd Berkner set up a Working Group under J. A. Ratcliffe to plan an Inter-Union Commission under the International Council of Scientific Unions (ICSU). With Ratcliffe in this task were V. Ilyin and V. Vitkevich (USSR), H. Sterky (Sweden), L.G.H. Huxley (Australia), J. van der Mark and E. Metzler (CCIR), and J. W. Findlay (USA), who acted as Secretary.

After three meetings, the group recommended that an Inter-Union Commission on Frequency Allocation (IUCAF) should be set up to be ready for the proposed Space WARC in 1963 and that that WARC should deal with the allocation of frequencies for both Space Science and RadioAstronomy.

Thus IUCAF was formed with Professor J. F. Denisse as the first Chairman and Dr. R. L. Smith-Rose as the first Secretary General. 